\title{
TEORIA CRÍTICA: UMA NOVA GERAÇÃO
}

\author{
MARCOS NOBRE
}

[1] Como referência influente da nova geração da Teoria Crítica na leitura de Adorno pode ser mencionado o trabalho de Brian O'Connor, Adorno's negative dialectics. Philosophy and the possibility of critical rationality (Cambridge: MIT Press, 2004).

[2] Nobre, Marcos. "Teoria Crítica hoje Hn: Peres, Daniel Tourinho e outros (orgs.). Tensões e passagens: críticăcomodernidade - Uma homenagem a Rucardo Terra. São Paulo: Singular, 2008 , p. 268

Para alcançar uma compreensão adequada do momento presente, a Teoria Crítica tem de ser capaz de entender como se configuram as lutas sociais emancipatórias. Com o declínio do socialismo como horizonte comum de emancipação na segunda metade do século XX, essa tarefa exigiu de saída um acerto de contas do campo crítico com o pensamento de Marx, que o inaugurou.

Em termos teóricos, o sentido mais amplo dessa mudança parece ter sido anunciado primeiramente por Adorno na década de $1960^{1}$. Diante da necessidade de renovação da perspectiva emancipatória, Adorno deu um passo atrás: mostrou que a orientação para a emancipação própria da obra de Marx tinha de ser reconfigurada a partir de suas fontes no pensamento de Kant e de Hegel. Os escritos de Horkheimer da década de 1930 haviam estabelecido uma nova relação entre teoria e prática no campo da Teoria Crítica, de tal modo que os dois termos já não se encontravam em "união" - como havia formulado Lukács -, mas no quadro de uma "orientação para a emancipação que tem de ser mantida a distância prudente da ação direta" ${ }^{2}$. Nesse sentido, Hegel permanece como fonte fundamental de uma teoria que não separa rigidamente o "descritivo" do "normativo". E, no entanto, Kant ganha novo peso em uma configuração em que o ponto de vista da teoria não coincide inteiramente e por princípio com a ação de uma classe social portadora do universal, em que teoria e prática não são mais pensados em união.

A busca de uma renovação da perspectiva crítica continua a ter como ponto de fuga a obra de Marx, mas passou a se dar, a partir da conceituação de Adorno, em um campo de forças formado pelas obras de Kant e de Hegel, explicitado por um exercício de críticas e de metacríticas sucessivas. Não se trata de "voltar a Kant" ou de "voltar a Hegel", sem mais, no sentido de se aferrar a uma das duas posições; trata-se de pensar os dois pontos de vista um contra o outro, sem ponto de parada previamente estabelecido, à maneira de um "diálogo" incessante entre uma e outra filosofia.

Esseéo estado de coisas de que partiu Habermas, por exemplo. Mesmo se a posição kantiana tem preeminência em sua teoria, Habermas 
se serve de Hegel como consumação da filosofia kantiana e ponto de partida para uma teoria da modernidade filosófica, por exemplo; ou, ao contrário, utiliza a filosofia hegeliana como contraponto para sua Teoria do Discurso, de inspiração kantiana. Também Axel Honneth, para continuarcom outro exemplo dentro do mesmo paradigma crítico, retomou a virada habermasiana em termos de um Hegel atualizado, pretendendo com isso explicitar e dar contornos mais concretos ao elemento comunicativo, central na "virada intersubjetiva" habermasiana.

Uma renovação teórica como essa tem exigências de várias ordens e dimensões. Exige não apenas, como já mencionado, a compreensão da lógica própria dos movimentos emancipatórios atuais, já irredutível ao modelo marxiano da classe revolucionária. A tarefa de produzir o diagnóstico do tempo o mais complexo e nuançado possível exige ainda uma reconfiguração do trabalho de pesquisa interdisciplinar, renovando o modelo teorizado por Horkheimer em seus escritos da década de 19303. Uma renovação como essa exige por fim, mas não por último, a busca de novas formulações para noções críticas fundamentais como as de "ideologia", "alienação", "reificação", ou "exploração".

Um traço distintivo de muitas contribuições originais de uma nova geração de integrantes do campo crítico é seu empenho na realização dessas tarefas. Algumas das mais instigantes delas na atualidade compõem o dossiê que se segue, composto a partir de contribuições de intelectuais de fora do país apresentadas no Cebrap, no Colóquio de Teoria Crítica de São Paulo 2011. Foram selecionadas não apenas por sua qualidade, mas também com o objetivo de tornar seus textos de referência disponíveis em português.

Robin Celikates publicou um dos mais importantes livros sobre os fundamentos da Teoria Crítica dos últimos anos4. Tomou como tarefa analisar o estado mais avançado da Teoria Tradicional — os trabalhos de Pierre Bourdieu e de Luc Boltanski - para incorporar criticamente as suas mais importantes inovações. Principalmente, Celikates insiste na conceituação da "virada intersubjetiva" de Habermas em um ponto essencial: o ponto de vista crítico não pode se colocar "às costas" dos atores sociais, seja sob a forma do "conhecimento científico", da "vanguarda política", ou de qualquer outro de seus sucedâneos.

Aorealizaresse movimento, sua posição pareceà primeiravista quase se confundir com a de Axel Honneth, com a qual tem muitas afinidades. Mas essa impressão não é inteiramente correta. Porque, dito de maneira mais precisa, Robin Celikates pretende alcançar mais longe: ressalta aqueles elementos distintivos do que se poderia chamar de "paradigma reconstrutivo" na atualidade, no qual se inclui o próprio Honneth. Seleciona alguns elementos da teoria de Habermas que merecem destaquee aprofundamento para que se torne possível a necessária explicitação da natureza do "intersubjetivo" e do "comunicativo" segundo o ponto de

\begin{abstract}
[3] Não apenas sobre os anos 1930 , mas também sobre toda a produção anterior, consulte-se a notável biografia intelectual realizada por John Abromeit, Max Horkheimer and the foundations of the Frankfurt School (Cambridge: Cambrige UP, 2011), igualmente um destacado teórico crítico da nova geração.
\end{abstract}

[4] Kritik als soziale Praxis. Gesellschaftliche Selbstverständigung und kritische Theorie. Frankfurt: Institut für Sozialforschung/Campus, 2009. 
[5] A esse respeito, outra referência incontornável na nova geração da Teoria Crítica é Rahel Jaeggi. Ver, por exemplo, o seu Entfremdung. Zur Aktualität eines sozialphilosophischen Problems (Frankfurt: Campus, 2005), e também o artigo "Repensando a ideologia" (Civitas, vol. $8, \mathrm{n}^{\circ}{ }_{1}$ 2008). Pode-se consultar com muito proveito também as contribuições do volume organizado por Jaeggi e Tilo Wesche, Was ist Kritik? (Frankfurt: Suhrkamp, 2009). vista dos próprios atores sociais, um ponto de vista que não pode mais ser afastado em nome de qualquer outro quelhe seria pretensamente superior. O que, por sua vez, repõe em novo patamar a tarefa de reformular problemas clássicos da tradição crítica, noções como as de "alienação" ou "ideologia".Afinal,em que sentidoé possível continuara empregaresses conceitos sem a pressuposição de contrapartidas como "falsa consciência" ou "consciência reificada", por exemplos?

Olivier Voirol tem como objetivo central de seus trabalhos atualizar, por meio de estudos empíricos em sociologia, noções críticas centrais como a de "indústria cultural". Esse objetivo é acompanhado não apenas pela crítica de contribuições de ponta da Teoria Tradicional - a sociologia de Bourdieu, por exemplo. Também exige uma reformulação da ideia mesma de "materialismo interdisciplinar". Para ficar apenas em um exemplo: porque a atualização de um conceito como "indústria cultural" exige uma cooperação interdisciplinar que não pode mais seguir o modelo clássico desenhado por Horkheimere praticado, mesmo que de maneira limitada, no Instituto de Pesquisa Social nos anos 1930. Mesmo que seja apenas para reconstruir primeiramente uma ideia moderna clássica de "cultura" em que a expressão "indústria cultural" possa readquirir seu caráter de estranheza, seu sentido de choque, como conjugação de termos julgados até então incompatíveis.

$\mathrm{Na}$ análise de Olivier Voirol, os principais desafios para a renovação do modelo do materialismo interdisciplinar hoje são dois. Primeiramente, é preciso repensar a relação entre teoria e prática, de tal maneira que isso não conduza seja a uma restauração da sua unidade — como no marxismo de modelo lukácsiano - , seja à quase separação entre os termos inaugurada por Horkheimer; mas, evitando essas duas posições, é preciso chegar a uma formulação em que a teoria seja capaz de fomentar as práticas emancipatórias que identifica em seu próprio trabalho de pesquisa. Isso exige, em segundo lugar, uma teoria disposta a produzir diagnósticos de tempo mais extensos e mais complexos. Esses dois desafios confluem e resultam, por fim, na ideia de que essa tarefa só pode ser realizada se for retomada a pretensão de pensar todos esses elementos em termos dialéticos.

Todo esse esforço de reconstrução da matriz marxiana acabou por fazer com que parte significativa do campo crítico abandonasse um projeto de renovação baseado no campo de forças formado pelo pensamento de Kant e de Hegel. Isso se deu, em grandes linhas, por dois caminhos bem diferentes.

Walter Benjamin desenvolveu seu modelo crítico simultaneamente a Max Horkheimer nos anos 1930, sendo que os dois modelos não só não podem ser reduzidos um ao outro como deram origem a "paradigmas críticos" bastante diferentes. Se o paradigma crítico inaugurado por "Teoria Tradicional e Teoria Crítica" segue as trilhas abertas pelo pecu- 
liar hegelianismo do Lukács de História e consciência de classe, o paradigma benjaminiano demonstra uma duradoura rejeição da posição de Hegel.

Após haver tentado atualizar sem sucesso a filosofia de Kant em alguns escritos de juventude, Walter Benjamin move-se para uma posição que recusa tanto a centralidade da ideia de "mediação" hegeliana quanto as pretensões transcendentais kantianas. O que resulta em uma produção em que se torna quase impossível distinguir o que poderia ser chamado de uma "teoria" do "choque" e da "montagem" de suas análises concretas da vida moderna "no auge do capitalismo". Com isso, retoma e continua Marx sem se prender ao campo de forças Kant-Hegel.Ao mesmo tempo, avança um modelo crítico que só pode ser continuado de maneira frutífera em análises concretas da modernidade.

É o que faz Jaeho Kang em suas análises dos "megaespetáculos globais", em particular sobre as Copas do Mundo de Futebol e sobre os Jogos Olímpicos ${ }^{6}$. Partindo do diagnóstico benjaminiano da crise das democracias como crises da representação pública dos políticos, Jaeho Kang vai contra a corrente, mostrando que maior "visibilidade" não significa "mais democracia". A confusão entre "visibilidade" e "controle democrático" não apenas está muito longe de ser óbvia. Pelo contrário, pode significar uma "estetização da política" em que a propaganda toma o lugar da política, em que o "visível" é a forma mais acabada da nova forma de dominação.

E, no entanto, nos termos benjaminianos em que se move, não pode haver outra resposta para essa tendência regressiva do que uma "politização da arte" que tome em conta as condições presentes de produção e de consumo da política. Daí o recurso à ideia benjaminiana de "fantasmagoria", que, aplicada à análise de "megaeventos globais", mostra as maneiras pelas quais a tecnologia certamente molda o comportamento coletivo, mas também é ela mesma moldada pelas massas. De tal maneira que o resultado não conduz nem à tecnofobia nem à exaltação do progresso técnico, mas a uma visão da tecnologia em termos de "experiência". E que tem como ponto de fuga algo como um "espaço público estético", em contraposição à ideia de uma "esfera pública deliberativa", cujo formalismo e abstração não levariam em conta justamente as condições concretas em que a política é encenada e exercida no momento presente.

Há, por fim, uma vertente crítica que recusa tanto sua fonte em Marx como o campo de forças que se formaria a partir dele, englobando as filosofias de Kant e de Hegel. De maneira geral, trata-se de uma vertente que tem suas raízes no pensamento de Heidegger. Ainda que se trate de uma vertente que não se filia explicitamente à Teoria Crítica - já que não se encontra nela uma adesão explícita à ideia central de orientação para a emancipação - , dificilmente seria possível caracterizá-la devidamente sem referência a alguma noção de crítica social. $O$
[6] Jaeho Kang iniciou trabalho de campo por ocasião da Copa do Mundo da África do Sul, em 2010, que prossegue até hoje e que se estende também à Copa do Mundo de 2014, que tem o Brasil como país-sede. 
[7] Ainda que o último Foucault se filie explicitamente a uma "ontologia do presente", inaugurada por Kant e que teria tido continuidade, segundo ele próprio, na forma de filosofia praticada "de Hegel à Escola de Frankfurt, passando por Nietzsche e Max Weber". Cf. Dits et écrits. vol. IV (1980-1988). Paris: Gallimard, 1994, p. 688. Não tratarei aqui do caso dos trabalhos críticos que se apoiam na obra de Derrida, cujo prolongamento mais interessante no presente parece ser o do "pós-colonialismo". Ver, por exemplo, Manoela Boatca e Sérgio Costa, "Postkoloniale Soziologie: ein Programm", in: Julia Reuter e Paula-Irene Villa (orgs.), Postkoloniale Soziologie. Empirische Befunde, theoretische Anschlüsse, politische Intervention, Bielefeld: transcript, 2010, assim como o conjunto de contribuições a esse volume. Um caso especial nesse quadro de tentativas de encontrar um novo lugar para a crítica fora do campo de forças Kant-Hegel e que também não será analisado aquiéo deJ.A. Giannotti, que constrói um "diálogo" entre Heidegger e Wittgenstein. Para uma apresentação e crítica da posição de Giannotti, ver Marcos Nobre, "O filósofo municipal, a Setzung e uma nova coalizão lógico-ontológica" (Novos Estudos, no 90, julho de 2011), bem como a resposta de Giannotti no mesmo número. No caso de Foucault, o livro de referência para um diálogo com o campo da Teoria Crítica é o de um outro representante destacado da nova geração, Martin Saar, Genealogie als Kritik. Geschichte und Theorie des Subjekts nach Nietzsche und Foucault (Frankfurt: Campus, 2007).

Recebido para publicação em 18 de maio de 2012.

\section{NOVOS ESTUDOS}

\section{CEBRAP}

93, julho 2012

pp. $23-27$ que mostra que não se trata de uma vertente heideggeriana em sentido estrito, mas antes de maneiras de explorar determinados veios da obra de Heidegger com intenção crítica. E esse uso crítico de determinados aspectos da obra de Heidegger encontrou em Foucault um modelo de análise que se estende de maneira fecunda até o presente7.

É esse o caso dos trabalhos de Ina Kerner. A começar pelo seu objeto: a literatura sobre dois dos mais importantes alvos dos movimentos sociais do século XX, o sexismo e o racismo. Nessa literatura, o ponto de vista da teoria e o da militância se sobrepõem de tal maneira que a tomar por objeto já é de si mesmo e por si mesmo um sinalizador das dificuldades nela presentes. Porque essa sobreposição de teoria e militância está na base de uma pressuposição que acaba sendo tomada como obviedade: a da intersecção de racismo e sexismo, tanto do ponto de vista das vítimas quanto dos movimentos que os combatem. A noção de "intersecção" surgiu como resposta à dificuldade de articulação trazida pela pluralização de objetivos emancipatórios simultâneos (em lugar do modelo da revolução como ato inaugural da verdadeira história). Trata-se de uma dificuldade que se coloca tanto para a teoria que pretende compreender esses objetivos de maneira unificada como para os próprios movimentos sociais que os perseguem.

Ao questionar essa obviedade, Ina Kerner pretende explicitar não só o pressuposto desse, digamos, "ímpeto unificador" da literatura, mas também revelar dimensões do racismo e do sexismo como que ocultadas ou deixadas de lado pela ideia de "intersecção". O que, por sua vez, pode permitir visualizar pontos de conexão e contato entre essas diferentes dimensões de uma maneira alternativa à visão trazida pela noção de "intersecção". E produzir uma tal cartografia da literatura a partir de categorias foucauldianas ressignificadas resulta em um panorama original e produtivo, tanto do ponto de vista da teoria como da prática dos movimentos sociais emancipatórios.

Do mesmo modo como a emancipação se pluralizou, sendo soletrada em diferentes vozes e pensada e realizada de diferentes maneiras, também hoje o campo crítico no sentido mais amplo do termo não se organiza mais em torno de Marx como referencial teórico inaugural partilhado. Mesmo tomada como campo plural e diverso, a Teoria Crítica é hoje apenas uma dentre muitas formas de crítica social radical. Para que possa mantervivas tanto sua referência original ao pensamento de Marx quanto sua capacidade de diagnóstico do tempo presente, precisa saber manter sempre fluidas e porosas as suas próprias fronteiras, precisa ser capaz de estabelecer parcerias e diálogos dentro do campo da crítica social em sentido mais amplo. Também esseé um dos objetivos do dossiê que se segue.

MARCOS NOBRE é professor no Departamento de Filosofia do IFCH da Unicamp e pesquisador do Cebrap. 